\title{
CONTRIBUIÇÕES DE UM CURSO EAD PARA O LETRAMENTO EM AVALIAÇÃO DE PROFESSORES DE LÍNGUAS ADICIONAIS PARA CRIANÇAS
}

\author{
CONTRIBUTIONS OF A DISTANCE-MODE COURSE TO THE \\ ASSESSMENT LITERACY OF TEACHERS OF ADDITIONAL \\ LANGUAGES TO CHILDREN
}

\author{
Gladys QUEVEDO-CAMARGO' \\ Juliana Reichert Assunção TONELLI ${ }^{2}$
}

\begin{abstract}
Resumo: A inserção de línguas adicionais nos anos iniciais escolares implica reformulação dos cursos de Letras e investimentos na formação docente para avaliar a aprendizagem (TONELLI; CRISTOVÃO, 2010; BUENO, 2020). Estudos apontam para a importância do desenvolvimento de conhecimentos sobre a avaliação de línguas adicionais e a urgência de desenvolver habilidades que possibilitem um trabalho mais bem informado com avaliação (QUEVEDO-CAMARGO, 2020). O objetivo deste artigo é apresentar uma análise temática (MINAYO, 2007) de diários reflexivos (REICHMANN, 2013) de participantes em um curso na modalidade de ensino a distância (EAD) sobre avaliação em contextos de ensino-aprendizagem de línguas adicionais para crianças, cuja escrita foi orientada por perguntas-guia. Buscaram-se evidências de impacto de um dos módulos do curso nas reflexões das cursistas sobre cinco conceitos básicos da área de avaliação: autenticidade, confiabilidade, efeito retroativo, praticalidade e validade (ISAACS, 2013; GREEN, 2014). Para a análise temática, utilizou-se o software Atlas.ti (Versão 9.0). Os diários sugerem que o módulo analisado foi bem-sucedido, visto que provocou reflexões sobre tais conceitos nas cursistas, que, em geral, não possuem formação específica para atuar no ensino de línguas adicionais para crianças, contribuindo para o Letramento em Avaliação (COOMBE, 2018) das participantes.
\end{abstract}

Palavras-chave: Letramento em avaliação de línguas. Ensino de línguas para crianças. Ensino a distância EAD. Diários reflexivos.
Abstract: The inclusion of additional languages in the early years of education implies the need to redesign language teacher education courses and improve teachers' assessment knowledge (TONELLI; CRISTOVÃO, 2010; BUENO, 2020). Several studies highlight the importance to develop knowledge about additional language assessment and the urgency to develop skills to enable well-informed work with assessment (QUEVEDO-CAMARGO, 2020). The aim of this article is to present a thematic analysis (MINAYO, 2007) of reflexive diaries (REICHMANN, 2013) written by participants of a distance-mode course on assessment in contexts of additional language teaching and learning for children, whose writing was guided by a set of questions. Evidence of possible impact exerted by one of the course modules on the participants' reflections in relation to the five key assessment principles - authenticity, reliability, validity, practicality, and washback (ISAACS, 2013; GREEN, 2014) - was sought. The thematic analysis was conducted by using the software Atlas.ti (Version 9.0). The diaries suggest that the analysed course module was successful as to raise participants' awareness concerning the concepts approached, considering that, in general, they have had no specific education to teach additional languages to children, thus contributing to the participants' assessment literacy (COOMBE, 2018).

Keywords: Language assessment literacy. Language teaching to children. Distance-mode teaching. Reflexive diaries.

1 Universidade de Brasília (UnB), Brasília, Distrito Federal, Brasil; gladys@unb.br;
https://orcid.org/0000-0002-4802-5296

2 Universidade Estadual de Londrina (UEL), Londrina, Paraná, Brasil; jtonelli@uel.br;

https://orcid.org/0000-0001-5102-5847 
- Contribuições de um curso EAD para o letramento em avaliação de professores de línguas adicionais para crianças

\section{Introdução}

No Brasil, o aumento da inserção de línguas adicionais, particularmente da língua inglesa, nos anos iniciais - Educação Infantil e Primeiro Ciclo do Ensino Fundamental $\left(1^{\circ}\right.$ ao $5^{\circ}$ ano) - impõe importantes desafios. Destaca-se a formação da profissional ${ }^{3}$ de Letras (TONELLI; CRISTOVÃO, 2010) para atuar nessa etapa de escolarização e para a avaliação da aprendizagem nessa etapa de vida escolar.

Conforme Rich (2019), em vários países onde a língua inglesa não é oficial, sua inserção nos anos iniciais tem impactado a formação de professoras. Porém, no contexto brasileiro, a ausência de documentos oficiais que orientem o ensino e o trabalho docente na Educação Infantil contribui para que essas profissionais se sintam pouco amparadas e expostas a uma formação inicial fragmentada, à mercê de iniciativas isoladas (TONELLI; QUEVEDO-CAMARGO, 2020).

Em concordância com McKay (2006), consideramos ser necessário um olhar específico para esse contexto de avaliação da aprendizagem de língua adicional por crianças pequenas, tendo em mente que, ao falarmos em crianças, temos uma amplitude etária que varia de poucos meses a aproximadamente 11 anos de idade, ou seja, o quinto ano escolar ${ }^{4}$. Ademais, as crianças, dependendo da faixa etária, estão em diferentes momentos de desenvolvimento físico, cognitivo e social, que estão interligados (MORAES; BATISTA, 2020).

Ainda são poucas as pesquisas que se ocupam em discutir a avaliação da aprendizagem de línguas na Educação Infantil bem como a formação docente para tal contexto (TONELLI; QUEVEDO-CAMARGO, 2018; BUENO, 2020). Tal cenário pode ser decorrente do fato de que 1) parece haver uma crença generalizada de que, por se tratar de estudantes em fase inicial de escolarização e que, portanto, estariam tendo seus primeiros contatos formais ${ }^{5}$ com a língua adicional, a avaliação não seria necessária; e, decorrente disso, 2) a avaliação, no contexto infantil, por não ser sistematizada e/ou formalizada na sala de aula, não tem sido objeto de investigação.

\footnotetext{
3 Neste artigo, optamos por utilizar o gênero feminino para nos referirmos a todos os gêneros.

4 De acordo com o Estatuto da Criança e do Adolescente (BRASIL, 1990), é considerada criança aquela até 12 anos incompletos.

5 Utilizamos o termo "contato" ou, ainda, "aprendizagem formal", para nos referirmos àquele que acontece e é sistematizado no ambiente escolar, haja vista que as crianças, geralmente, têm contato informal com a língua inglesa por meio de jogos digitais, programas de televisão, músicas, etc.
} 
Assim, justifica-se a urgência de trabalhar o desenvolvimento de conhecimentos sobre a avaliação de línguas adicionais com essas profissionais. Tal trabalho inserese no que se chama de Letramento em Avaliação de Línguas (LAL) (BRINDLEY, 2001; SCARAMUCCI, 2016; QUEVEDO-CAMARGO; SCARAMUCCI, 2018), que, em sua essência, abarca iniciativas que objetivam propiciar aos diferentes agentes educacionais - mães, pais, responsáveis, autoridades educacionais, elaboradoras de exames, e sobretudo professoras - conhecimentos que lhes permitam compreender os diferentes aspectos envolvidos no processo avaliativo de forma que possam refletir criticamente sobre eles a partir de suas próprias realidades e tomar decisões bem informadas.

Inbar-Lourie (2008) e Hasselgreen (2012) chamam a atenção para o fato de que, em geral, professoras de línguas têm baixo letramento em avaliação por falta de formação acadêmica. No Brasil, um levantamento feito por Quevedo-Camargo (2020) indica situação semelhante e corrobora o que já havia sido afirmado por Scaramucci (2016).

Dessa feita, o objeto deste artigo é apresentar uma análise temática (MINAYO, 2007) dos relatos reflexivos (REICHMANN, 2013) escritos das cursistas relativos a um dos módulos de um curso de extensão ministrado na modalidade extensão no primeiro semestre de 2020 pelas autoras, em formato de ensino a distância (EAD), sobre avaliação em contexto de ensino e aprendizagem de línguas adicionais para o público infantil. Nessa análise, nosso intuito foi identificar evidências de impacto dos conceitos abordados no módulo nas reflexões das cursistas, visto serem primordiais para a elaboração de tarefas e instrumentos avaliativos.

O texto prossegue com três seções. Na primeira, discorremos sobre o conceito de LAL e sua contribuição para a avaliação no ensino infantil. Na segunda, contextualizamos a iniciativa de LAL realizada e o foco da nossa análise, e na terceira seção, apresentamos essa análise. Nossas considerações finais encerram o artigo.

\section{O Letramento em Avaliação de Línguas e sua contribuição para o contexto de ensino infantil}

A partir de uma expansão do termo Letramento, relacionado às habilidades de escrever e ler (SOARES, 1999), passou-se a utilizar essa palavra com o significado de conhecimentos, habilidades e competências relativas a diversos domínios do nosso cotidiano (TAYLOR, 2013). Stiggins (1991) valeu-se dessa noção para propor o termo Assessment Literacy - Letramento em Avaliação, chamando a atenção da comunidade educacional e acadêmica estadunidense para a responsabilidade que tinham ao tomar decisões importantes, com base em resultados de avaliações, que afetariam grandemente 
- Contribuições de um curso EAD para o letramento em avaliação de professores de línguas adicionais para crianças

a vida das estudantes. Ele propunha que se buscasse compreender quais conhecimentos e habilidades deveriam constituir tal letramento, defendia que a profundidade desse letramento deveria ser diferenciada dependendo do agente educacional envolvido (pais, mães ou responsáveis, professoras, autoridades educacionais etc.), e posicionava-se a favor do desenvolvimento de programas de Letramento em Avaliação específicos para as necessidades desses agentes educacionais.

Brindley (2001) trouxe o conceito para a área de línguas e a formação de professoras, dividindo-o em quatro frentes: as práticas avaliativas utilizadas pelos docentes; seus saberes e suas competências; suas necessidades de desenvolvimento profissional; e o conteúdo de programas de desenvolvimento profissional voltados para a avaliação. Desde então, diversos autores propuseram definições para Letramento em Avaliação de Línguas (LAL). Neste artigo, adotamos a definição de Coombe (2018, p. 10, tradução nossa ${ }^{6}$ ):

1. Letramento em Avaliação é o conhecimento e a compreensão abrangente sobre as competências e habilidades dos alunos, sobre como interpretar os dados coletados a partir das avaliações, e sobre como usar a interpretação de tais dados para aprimorar o aprendizado e o desenvolvimento das alunas por meio da tomada de decisões adequadas;

2. O know-how fundamental e essencial para elaborare aplicar itens confiáveis de testes em termos de princípios de elaboração, especificações, confiabilidade, validade e padronização. A atribuição padronizada de notas ou escores também é um elemento inerente à avaliação. Com relação aos programas escolares ou cursos, as professoras precisam entender os objetivos do curso e alinhar suas práticas formais e informais de avaliação para determinar o quanto os objetivos estão sendo atingidos e como as práticas de ensino/aprendizagem podem ser mais eficazes. Portanto, não só avaliadoras profissionais, mas também as professoras, precisam desenvolver o letramento em avaliação.

\footnotetext{
6 No original: "1. Assessment literacy is the knowledge about, and a comprehensive understanding of, students' skills and ability, interpreting the collected data from the assessments, and using these interpretations to improve students' learning and development by making appropriate decisions. 2. The fundamental knowhow essential for constructing and implementing reliable test items in terms of the principles of test design, test specifications, reliability, validity and standardization. Standardized scoring or marking is also an integral element of assessment. With regards to school courses/programs, teachers need to understand the objectives of the course and align their formal and informal assessment practices to determine how far objectives are met and how teaching/learning practices may be made more effective. Therefore, not only professional assessors, but also program teachers, need to develop assessment literacy".
} 
Trabalhos brasileiros que abordam os conceitos inerentes à LAL para atuar junto ao público infantil começam a despontar. Preocupadas em conhecer o nível de LAL das docentes de inglês para crianças, Tonelli e Quevedo-Camargo (2019) buscaram identificálo em um grupo de alunas de um curso de pós-graduação lato sensu em Ensino de Inglês para Crianças, também na modalidade EAD e de participantes inscritos em um evento bianual voltado à formação de professores de línguas adicionais para crianças pequenas. Essa investigação foi feita por meio de um questionário on-line utilizando o GoogleForms, adaptado da Language Assessment Literacy Survey elaborado por Kremmel e Harding $(2019)^{8}$. Essa survey, que chamamos de questionário, foi composta por 70 assertivas que versavam sobre temas ligados à avaliação no contexto investigado ${ }^{9}$, conforme reportado pelas autoras. Foram obtidas 151 respostas de docentes de várias partes do país. Os resultados indicaram que a grande maioria das participantes considera que não sabe ou sabe pouco sobre assuntos cruciais para o trabalho docente em avaliação e para a integração do ensino, aprendizagem e avaliação ao atuar com crianças pequenas.

O trabalho de Moraes e Batista (2020) ressalta a importância de a professora ter conhecimento sobre avaliação, linguagem e, em conformidade com McKay (2006), entendimento sobre os níveis de desenvolvimento da criança. Para os autores, no contexto infantil, deve-se incluir outros elementos não presentes quando se trata de adultos, como saber o que a criança consegue fazer em termos de coordenação motora fina e grossa, por exemplo, pois a ausência de conhecimentos sobre o aspecto motor pode interferir na natureza das atividades avaliativas e comprometer tanto o processo avaliativo quanto o de aprendizagem.

\section{Contextualizando o estudo}

O curso de extensão "Avaliação da aprendizagem de inglês por crianças" ocorreu nos meses de abril e maio de $2020^{10}$ e foi ofertado na modalidade a distância (EAD) por meio do Núcleo de Ensino a Distância (NEAD) e do Laboratório de Tecnologia Educacional da Universidade Estadual de Londrina - UEL. Participaram do curso 43 pessoas, cujos perfis são apresentados no quadro 1, a seguir.

\footnotetext{
7 Disponível em: http://wp.lancs.ac.uk/Itrg/projects/language-assessment-literacy-survey/

80 questionário foi traduzido e adaptado por nós, tendo em mente o contexto de ensino de línguas adicionais para crianças no Brasil.

9 No questionário on-line foi incluído o Termo de Consentimento Livre Esclarecido(TCLE) no qual a respondente declarou ciência e concordância com as informações contidas na seção "Apresentação ao participante".

10 A elaboração deste curso foi um dos resultados de pesquisa de pós-doutoramento feita pela segunda autora deste artigo, sob a supervisão da primeira.
} 
- Contribuições de um curso EAD para o letramento em avaliação de professores de línguas adicionais para crianças

Quadro 1. Perfil dos cursistas

\begin{tabular}{|c|c|c|c|}
\hline $\begin{array}{l}\text { Idade } \\
\text { média }\end{array}$ & $\begin{array}{l}\text { Região } \\
\text { do país }\end{array}$ & $\begin{array}{c}\text { Nível de } \\
\text { escolarização }\end{array}$ & $\begin{array}{l}\text { Experiência profissional no ensino de } \\
\text { inglês para crianças }\end{array}$ \\
\hline 18 a 38 anos & $\begin{array}{l}\text { PR - } 73 \% \\
\text { SP - } 15 \% \\
P A-2 \%\end{array}$ & $\begin{array}{l}\text { Graduandas - 12\% } \\
\text { Graduadas - 37\% } \\
\text { Pós-graduandas - 23\% } \\
\text { Pós-graduadas - 28\% }\end{array}$ & $\begin{array}{l}\text { Já atuou ou está atuando - } 78 \% \\
\text { Nunca atuou e/ou não está atuando - 22\% }\end{array}$ \\
\hline
\end{tabular}

Fonte: Elaboração própria

O quadro 1 mostra que as cursistas são um público jovem e, em sua grande maioria (88\%), em formação continuada, visto que somente 12\% eram graduandas. Tal cenário indica, conforme discutiremos mais adiante, que a avaliação de línguas no contexto infantil tem sido pouco estudada na formação inicial. Além disto, 78\% delas atuou ou estava atuando no ensino de inglês nos anos iniciais, o que ressalta a importância de terem mais acesso a conhecimentos sobre avaliação.

O curso foi ministrado em oito módulos compostos por videoaulas assíncronas com duração de aproximadamente uma hora cada, com exceção do Módulo 1, que foi introdutório. Sua função foi propiciar familiarização ao ambiente virtual de aprendizagem (AVA) utilizado e explicitar os objetivos do curso, as formas de interação, as questões éticas ${ }^{11}$ referentes à participação e à autorização (ou não) do uso dos dados provenientes do curso para pesquisas futuras, bem como questões burocráticas.

O Módulo 2, intitulado "Visões sobre avaliação da aprendizagem de línguas adicionais na educação infantil", objetivou suscitar reflexões sobre a avaliação, seus componentes e suas relações complexas em contextos educacionais. Foram apresentados vídeos com depoimentos de agentes educacionais (professoras, alunas e coordenadora pedagógica), que expressavam como compreendem a avaliação da aprendizagem de línguas. A partir da apresentação dos vídeos, as cursistas foram estimuladas a redigir diários reflexivos após o término de cada módulo, prática que foi denominada de Think it over ${ }^{12}$.

11 O curso fez parte de atividades desenvolvidas no Projeto de Pesquisa "Avaliação da Aprendizagem de Línguas Estrangeiras nas Séries Iniciais de Escolarização", registrado na Pró-reitoria de Pesquisa e Pós-graduação da Universidade Estadual de Londrina, sob n 11.779 . Aprovação do Comitê de Ética Envolvendo Seres-humanos CAAE 07609319.4.0000.5231

12 Não houve solicitação de diário reflexivo após o primeiro e o último módulos. 
Nos Módulos 3 a 6, as cursistas foram orientadas a ler artigos acadêmicos que aprofundavam a temática explorada em cada um. Além disso, nos Módulos 3 a $7^{13}$, perguntas-guia foram sugeridas às cursistas para que pudessem elaborar suas reflexões e registrá-las nos diários reflexivos. Essas perguntas estão no Quadro 2, a seguir.

Quadro 2. Perguntas-guia para elaboração dos diários reflexivos nos módulos 3 a 7

- Quais aspectos explorados no módulo me chamaram mais atenção?

- Há algum ponto que reconheço que já faço ou que preciso incorporar em minha prática?

- Quais ideias me ocorreram quando li os textos ou assisti às aulas?

- Reconheço na temática explorada pontos que gostaria de me aprofundar?

Fonte: Elaboração própria

O Módulo 3, intitulado "Para início de conversa", objetivou situar as cursistas em relação ao lugar da avaliação nos diferentes níveis educacionais, desde a sala de aula até o nível mais macro representado pelas políticas públicas nacionais. O Módulo 4, intitulado "Contextos e agentes da avaliação de línguas adicionais na educação infantil", partiu da reflexão anterior sobre questões contextuais gerais e concentrou-se nos agentes - pais, mães, responsáveis, alunos, professores, coordenadores, diretores e autoridades educacionais - inseridos no contexto de ensino de línguas adicionais na Educação Infantil. O Módulo 5, chamado "Funções e objetivos da avaliação de línguas adicionais na educação infantil", trouxe para reflexão a importância da definição dos objetivos de aprendizagem e a relação dessa definição com as funções clássicas da avaliação - diagnóstica, formativa e somativa. O Módulo 6, "Conceitos básicos da avaliação de línguas adicionais", abordou cinco conceitos relevantes para avaliação de línguas adicionais: validade, confiabilidade, praticalidade, autenticidade (GREEN, 2014; RETORTA; MAROCHI, 2018) e efeito retroativo (potencial de impacto) (QUEVEDO-CAMARGO, 2014). Os Módulos 7 e 8 - "Atividades avaliativas parte 1 e 2", de caráter mais prático, buscou levar as cursistas a refletir sobre modalidades de práticas avaliativas e suas demandas linguísticas, cognitivas e interacionais, entre outras. Embora o Módulo 7 tenha se concentrado em atividades práticas, contemplou também aspectos teóricos, como a elaboração de rubricas e seu papel no ensino para crianças pequenas. O Módulo 8 foi totalmente dedicado à análise prática de atividades.

Para a análise dos diários reflexivos, adotamos a abordagem qualitativa e interpretativista (MARCONI; LAKATOS, 2003). A exemplo de outros trabalhos dessa

13 Como o Módulo 8 tinha um caráter mais prático, as perguntas relativas a ele versavam sobre a análise das atividades apresentadas. 
- Contribuições de um curso EAD para o letramento em avaliação de professores de línguas adicionais para crianças

natureza ou de natureza mista que analisaram textos produzidos oralmente ou por escrito por participantes (SHEEHAN; MUNRO, 2019, por exemplo), nesta pesquisa os diários reflexivos dos Módulos 3 a 6 foram analisados por meio do software Atlas.ti (Versão 9.0) com base nos temas das perguntas-guia sugeridas, que se transformaram em categorias temáticas para análise conforme apresentadas no Quadro 3. A cada uma, atribuímos a elas códigos para agrupamento e busca no software Atlas.ti.

Quadro 3. Categorias temáticas e códigos gerados para rastreamento

\begin{tabular}{|l|c|}
\hline \multicolumn{1}{|c|}{ Categoria temática } & Código \\
\hline O que chamou a atenção da cursista no módulo & 1 \\
\hline Algo que a cursista declara já fazer & $2 \mathrm{~A}$ \\
\hline Algo que a cursista acha que precisa incorporar na sua prática & $2 \mathrm{~B}$ \\
\hline Ideias ou reflexões suscitadas pelo módulo & 3 \\
\hline O que a cursista declara querer aprofundar & 4 \\
\hline
\end{tabular}

Fonte: Elaboração própria

Os diários reflexivos foram agrupados em quatro arquivos Word - um por módulo (3 a 6). Cada cursista foi também codificada, recebendo a letra " $\mathrm{C}$ " e um número; assim, por exemplo, no arquivo Módulo 3, o trecho do diário reflexivo da Cursista 1 foi identificado como $\mathrm{Cl}$. Na fase seguinte, os quatro arquivos foram inseridos no software e rastreados a partir de leitura cuidadosa em busca das categorias temáticas (provenientes das perguntas-guia) em cada módulo.

Por questões de espaço, neste artigo optamos por apresentar somente a análise de um dos módulos. O escolhido foi o Módulo 6, justamente por ter abordado os conceitos centrais para a elaboração de instrumentos avaliativos: autenticidade, confiabilidade, efeito retroativo, praticalidade e validade. Esse foi, certamente, o módulo com conteúdo mais teórico e, portanto, provavelmente mais distante do cotidiano das cursistas. Harding e Kremmel (2016) defendem que as professoras, por serem as principais usuárias da avaliação de línguas, precisam estar familiarizadas com os princípios da avaliação de línguas, enquanto Fulcher (2012) afirma que elas devem ter conhecimentos sobre como elaborar tarefas e instrumentos avaliativos. Esses cinco princípios ou conceitos são considerados, pela literatura em avaliação educacional e de línguas ${ }^{14}$, como básicos e fundamentais para a elaboração de quaisquer instrumentos avaliativos, sejam eles para avaliação formativa, somativa ou de larga escala.

14 Ver, por exemplo, Pellegrino, Chudowsky e Glaser (2001), Isaacs et al. (2013), Green (2014), e Skinner (2017). 


\section{A análise do Módulo 6}

A busca por excertos relativos às categorias temáticas nos diários reflexivos relativos ao Módulo 6, com a utilização do software Atlas.ti (V.9), produziu os seguintes dados:

Quadro 4. Excertos do Módulo 6 por categoria temática

\begin{tabular}{|c|l|c|}
\hline Código & \multicolumn{1}{|c|}{ Categoria temática } & No de excertos \\
\hline 1 & O que chamou a atenção da cursista no módulo & 27 \\
\hline 2A & Algo que a cursista declara já fazer & 11 \\
\hline 2B & Algo que a cursista acha que precisa incorporar na sua prática & 05 \\
\hline 3 & Ideias ou reflexões suscitadas pelo módulo & 38 \\
\hline 4 & O que a cursista declara querer aprofundar & 8 \\
\hline Total & & 89 \\
\hline
\end{tabular}

Fonte: Elaboração própria

No Quadro 4, chama a atenção o número de excertos nas categorias temáticas de códigos 1 e 3, que parecem indicar que o Módulo 6 tenha, de alguma forma, desafiado as cursistas a refletirem sobre os conceitos apresentados - validade, confiabilidade, praticalidade, autenticidade e efeito retroativo - e as relações desses conceitos com a prática docente no contexto de ensino de línguas adicionais para crianças. $\mathrm{O}$ artigo acadêmico proposto para leitura após o Módulo 6 foi "A validação de um teste" (RETORTA; MAROCHI, 2018), que explicita os conceitos apresentados.

Foram separados os excertos referentes a esses códigos - 27 do Código 1 e 38 do Código 3 - em dois arquivos e repetidos os procedimentos de análise temática (MINAYO, 2007) por meio do software Atlas.ti tendo como categorias os cinco conceitos fundamentais trabalhados no Módulo 6. Criamos uma sexta categoria - Comentários gerais - para abarcar trechos dos diários reflexivos que apresentassem indícios de impacto do módulo que não se encaixassem nas categorias anteriores. No Quadro 5, apresentamos o resumo dessas categorias: 
- Contribuições de um curso EAD para o letramento em avaliação de professores de línguas adicionais para crianças

Quadro 5. Categorias temáticas para análise dos excertos dos Códigos 1 e 3 no Módulo 6

\begin{tabular}{|l|l|c|}
\hline \multicolumn{1}{|c|}{ Categoria } & \multicolumn{1}{|c|}{ Foco de busca } & $\begin{array}{c}\text { Código } \\
\text { atribuído }\end{array}$ \\
\hline Autenticidade & $\begin{array}{l}\text { Trechos relativos ao conceito autenticidade, com ou sem } \\
\text { menção explícita ao termo }\end{array}$ & A \\
\hline Confiabilidade & $\begin{array}{l}\text { Trechos relativos ao conceito confiabilidade, com ou sem } \\
\text { menção explícita ao termo }\end{array}$ & C \\
\hline Efeito retroativo & $\begin{array}{l}\text { Trechos relativos ao conceito efeito retroativo ou ao impacto } \\
\text { da avaliação em alguma dimensão do ensino-aprendizagem } \\
\text { ou em algum agente, com ou sem menção explícita ao termo }\end{array}$ & ER \\
\hline Praticalidade & $\begin{array}{l}\text { Trechos relativos ao conceito praticalidade, com ou sem } \\
\text { menção explícita ao termo }\end{array}$ & P \\
\hline Validade & $\begin{array}{l}\text { Trechos relativos ao conceito validade, com ou sem menção } \\
\text { explícita ao termo }\end{array}$ & V \\
\hline Comentários gerais & Trechos relativos ao Módulo 6 como um todo & CG \\
\hline
\end{tabular}

Fonte: Elaboração própria

A análise dessas categorias é apresentada nos Gráficos 1 e 2, a seguir.

Gráfico 1. Excertos do Código 1: O que chamou a atenção da cursista no módulo

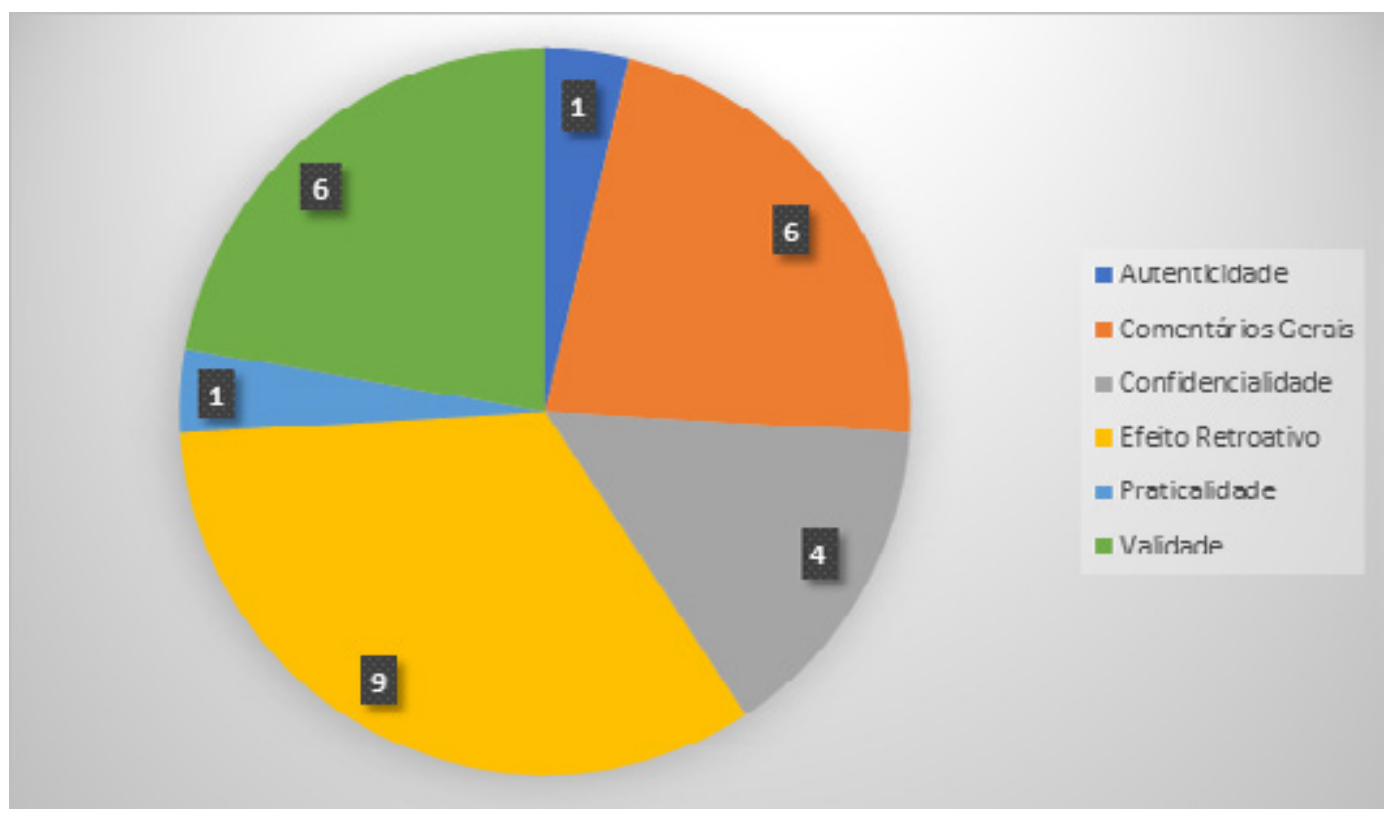

Fonte: Elaboração própria

Como demonstrado no Gráfico 1, dos 27 excertos identificados no Código 1, o que mais se destacou foi o conceito de efeito retroativo. As cursistas relataram, conforme 
evidenciado nos excertos a seguir, terem tido contato recente com ele e também reconheceram sua relevância, particularmente no contexto de ensino para crianças.

O outro aspecto é o efeito retroativo (washback effect), que deveria ser muito mais falado e apresentado nas licenciaturas. Eu só fui conhecer o termo em um curso de metodologias e fiquei encantada como é verdadeira essa questão. (C5)

Módulo superinteressante, pois temos que avaliar tantas coisas que já estão no automático e que se esquecermos podemos causar um sério problema para nós mesmos e principalmente para nossos educandos. (C23)

Eu não conhecia a definição de efeito retroativo, até esse ano. (C27)

O segundo conceito mais comentado foi validade. As cursistas relataram desconhecimento, como mostram os excertos abaixo.

Dessa vez o módulo tratou de algo novo para mim, a questão da validade dos testes. (C37)

Acredito que tudo neste módulo seja interessante e de grande utilidade, porém o conceito de validade que segue a linha da utilidade, relevância e interpretações do teste $(\mathrm{Cl} 7)$

A questão da validade dos testes foi algo que me surpreendeu, percebi que muitas coisas precisam ser levadas em conta quando falamos sobre isso, muitas das nossas percepções podem afetar os testes que elaboramos para os nossos alunos, daí a importância de testes realmente justos e validados. (C37)

O terceiro conceito mais comentado foi a confiabilidade, que, como mostram os excertos, levou as cursistas a refletirem particularmente sobre aspectos relativos à inclusão das crianças e à afetividade na sala de aula.

O que mais me levou a pensar foi o tópico confiabilidade, pois ao envolver tanto as emoções e momentos de alunos e o professor, acredito que pensarei melhor em quanto isso pode afetar na hora da avaliação. (C33)

Esse módulo me chamou mais atenção no cuidado, que devemos estar atentos na hora de fazer uma avaliação, cada detalhe que devemos prestar atenção, desde o ambiente até o psicológico de cada aluno. Pensar também além da sala de aula ao preparar uma avaliação, qual o contexto dos alunos, tentar incluir todos eles para que todos consigam realizar a prova. (C21)

Quanto ao único excerto relativo à praticalidade, houve somente um comentário, que se refere especificamente aos custos provenientes do uso de fotocópias ou materiais como cartolina ou papel sulfite, por exemplo, ao se planejar atividades avaliativas.

os tópicos que me chamaram mais a atenção em termos de avaliar crianças é o fator confiabilidade [...], dentre os fatores também, a questão dos custos (C2) 
- Contribuições de um curso EAD para o letramento em avaliação de professores de línguas adicionais para crianças

\section{Com relação à autenticidade, C21 comentou que}

é muito importante para que aquilo não seja repetitivo, para que eles vejam o idioma inserido no real, situações que eles podem acabar se deparando no futuro [...].

Com relação ao Código 3, a análise gerou o seguinte gráfico:

Gráfico 2. Excertos do Código 3: Ideias ou reflexões suscitadas pelo módulo

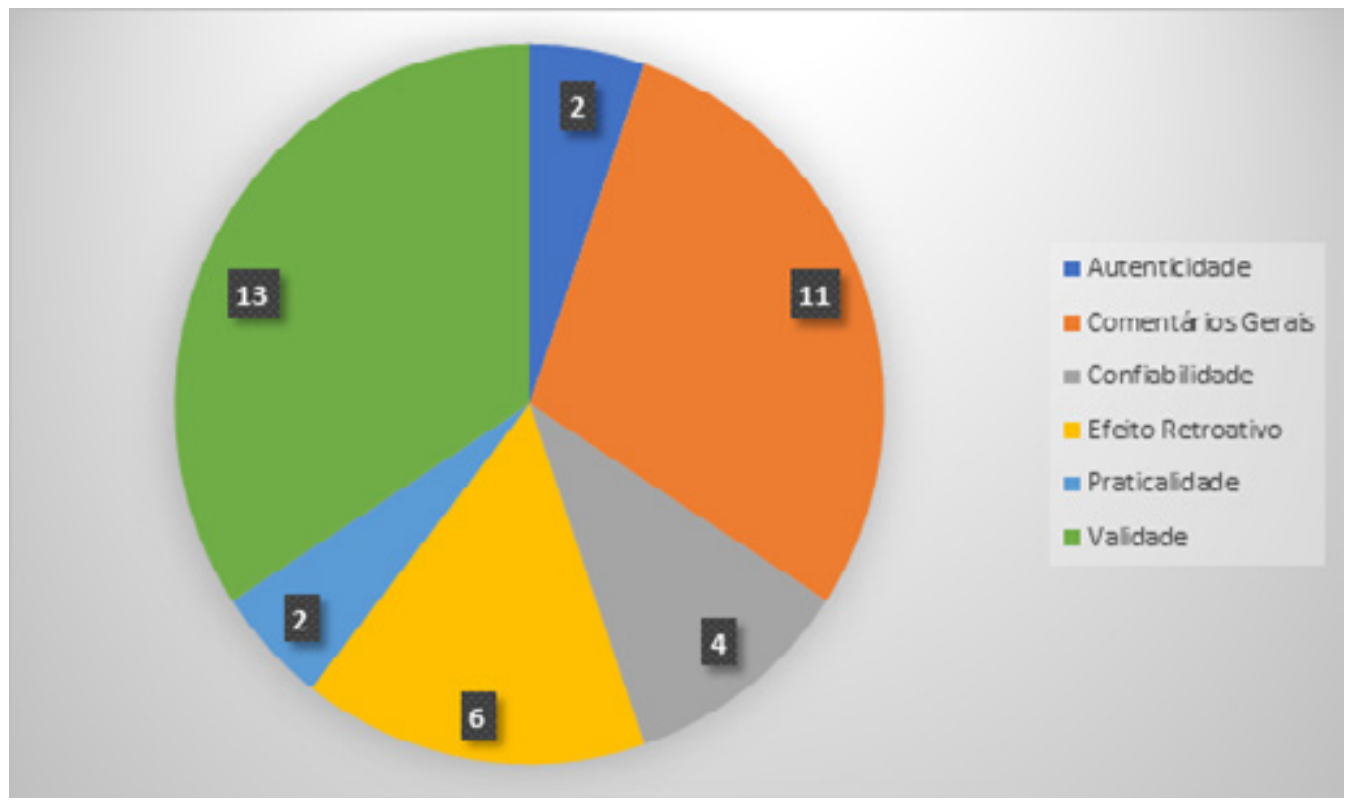

Fonte: Elaboração própria

Nos 38 excertos do Código 3, houve novamente menção aos conceitos fundamentais. O mais referenciado foi a validade que, de acordo com as cursistas, envolve considerar as particularidades da criança, e ponderar o quão significativa a tarefa avaliativa é para ela. No excerto a seguir, esta ideia fica evidenciada:

[...] precisa ser levado em conta o quão significativo aquele conteúdo será para a vida social e particular do aluno. (C31)

Outro aspecto mencionado nos diários foi como os instrumentos podem e devem ser adequados a cada faixa etária e aos contextos, ainda que aparentemente possam ser os mesmos, como é o caso, por exemplo, dos mesmos anos escolares. Tais preceitos encontram respaldo nos trabalhos de Bueno (2020) e Moraes e Batista (2020), por exemplo, uma vez que apontam a importância da adequação dos instrumentos e das atividades avaliativas quando falamos em avaliação do processo de aprendizagem no ensino infantil. 
Os diários reflexivos apontam, ainda, que o conceito de validade era novo para a maioria das cursistas, confirmando a pesquisa de Tonelli e Quevedo-Camargo (2019) sobre o baixo grau de LAL por parte de docentes que atuam no ensino de línguas adicionais junto às crianças. Os dois excertos a seguir exemplificam tais pontos:

Achei muito interessante o exemplo [...] sobre a aplicação de provas iguais em turmas que podem ter contextos, necessidades, conhecimentos diferentes. Essa é uma prática bastante comum como professores que atuam na mesma instituição de ensino, porém em turmas diferentes, mas na mesma etapa de aprendizagem. A reflexão que toma conta desse tema é a de que até que ponto o que um colega meu utilizou na escola, poderá ser válido para minha turma. (C26)

Tratando-se de crianças aprendendo inglês, creio que seja ainda mais importante refletir sobre essas questões, é necessário estabelecer muito claramente o que queremos avaliar, tendo em vista o que de fato ensinamos. (C22)

O conceito de efeito retroativo foi o segundo mais mencionado nessa etapa de análise. Tendo em conta o contexto, o excerto a seguir indica reflexões sobre a importância da avaliação para além de algo pontual ou momentâneo.

É interessante pensar que uma avaliação não tem somente a função de atingir o aprendizado do aluno que a realizou, mas ela pode atingir um campo muito mais amplo. (C14)

De nossa perspectiva, o fato de C14 concluir que a avaliação vai muito além de verificar a aprendizagem, podendo refletir também na recondução da aula e até do seu planejamento (MISTRY; SOOD, 2015), parece indicar que sua concepção sobre o ato de avaliar se restringia ao resultado e não ao processo avaliativo.

A confiabilidade, terceiro conceito mais mencionado, mostrou-se localizada na afetividade que permeia o ato de avaliar crianças aprendendo uma língua adicional. Nesse quesito, os relatos registraram a possibilidade de o estresse e a ansiedade - inerentes aos processos avaliativos - comprometerem a confiabilidade de uma avaliação. Os próximos excertos ilustram tal aspecto.

[...] relação entre professor e aluno interfere muito nos resultados [...] (C14).

[...] para evitar que a avaliação cause algum tipo de ansiedade ou estresse, ele seja bem típico do cotidiano dos alunos, assim eles podem engajar-se mais e performar seu conhecimento melhor. (C36)

A análise aponta também que, ao se assumirem professoras de inglês para crianças (TONELLI; CRISTOVÃO, 2010), as cursistas indicam que a confiabilidade envolve, ainda, colocar-se no lugar do outro, como comprova este excerto: 
- Contribuições de um curso EAD para o letramento em avaliação de professores de línguas adicionais para crianças

Como professora (de crianças) penso bastante em empatia e perceber o outro como "o outro". (C35).

Por fim, a autenticidade e a praticalidade, embora menos mencionadas, mobilizaram reflexões sobre a influência de fatores externos à escola no processo avaliativo. Nas palavras de $\mathrm{C} 14$,

Como estudei todos os meus anos no sistema público, percebo que, no quesito praticidade, o campo do custo da avaliação se faz bem presente, a escola depende das verbas do governo, que são limitadas, e por isso sempre foi comum onde estudei faltarem desde materiais básicos, como cartolinas, até outros mais caros, como bons computadores. (C14)

Importa considerar que, para que uma atividade seja significativa, muitas vezes serão necessários recursos materiais que a viabilizem. Isso nos leva a concluir que as cursistas reconhecem que conceitos como validade, autenticidade e praticalidade, por exemplo, não são dissociados, conforme ilustrado a seguir.

Em relação à praticidade, penso que com a experiência, errando e acertando, vamos aprendendo a "facilitar" nossa vida e a do aluno. Com a prática vemos que, ao preparar uma avaliação, devemos pensar também em como será o processo de correção. (C29)

[...] conceito de autenticidade me fez pensar muito nas aulas de gêneros textuais [...] a importância da autenticidade na prática em sala de aula, pois ela cria um engajamento entre o aluno, a atividade e uma futura circulação do resultado dessa atividade. (C14)

$\mathrm{Na}$ categoria comentários gerais, destacam-se reflexões que mostram o quanto a avaliação pode e deve ser explorada dadas as suas especificidades, a sua abrangência e relevância no cotidiano da educação infantil. Dos 17 excertos categorizados como comentários gerais (6 no código 1 e 11 no código 3), destacam-se a complexidade da avaliação, suas consequências positivas e negativas, o sentimento de despreparo profissional, a avaliação de estudantes com algum tipo de deficiência, dentre outros. Os trechos subsequentes ilustram esses apontamentos.

[...] apesar da avaliação ser parte inerente de todo processo de ensino, percebo que não estamos devidamente preparados para fazê-lo como realmente deveria. Mas entendo que esse processo tem caminhado, ainda que a passos pequenos, para atender as finalidades. (C11)

[...] estava pensando em como a avaliação é algo que exige de nós, professores, uma atenção absurda para ser o mais "democrática". (C13) 
Devemos parar de ignorar que em nossas salas, nos dias de hoje, encontramos com mais frequência alunos que fazem uso de medicamentos, pois sofrem de transtornos mil e outras doenças/ deficiências. É triste saber que podemos fazer parte do processo de exclusão destes alunos, sabendo que somos aqueles que deveriam dar oportunidades. Levarei estes conceitos anotados comigo de agora em diante para sempre me lembrar de dar o meu melhor. (C13)

Os excertos revelam ainda que o tema, conforme exposto anteriormente, tem sido pouco discutido, especialmente no contexto de línguas adicionais para crianças.

Nunca pensei e não me recordo em ter estudado os conceitos básicos da avaliação [...] (C23)

Antes dessa aula, não conhecia os cinco conceitos (C22)

Eu estou de queixo caído, pois eu nunca havia assistido uma aula sobre conceitos básicos de avaliação! Eu tô de cara! Muito conhecimento! (C35)

Durante a análise dos diários decorrentes do Módulo 6, foi possível identificar também que o capítulo disponibilizado como leitura complementar contribuiu para promover tais reflexões, conforme explicitado no excerto a seguir:

[...] o texto teórico conseguiu me trazer uma clareza de qual o meu propósito com aquela avaliação, e com toda certeza pensarei nesse aspecto ao avaliar um aluno a partir de agora, pois quero sempre avaliar aquilo que acho que deve ser cobrado com base nas atividades e aulas sobre o tema, e não, por exemplo, pegar algo pronto da internet sem adaptar para a realidade da minha turma. (C33)

Esses relatos corroboram o que a literatura já traz sobre a carência de letramento em avaliação de línguas dos docentes em geral (INBAR-LOURIE, 2008; HASSELGREEN, 2012, entre outros), e evidenciam que não é diferente em meio aos profissionais que atuam no ensino para o público infantil.

Antes de tecermos nossas considerações finais, depreendemos que, a partir da análise realizada, o módulo abordou elementos considerados centrais do LAL os quais servem para pensar a avaliação tanto formativa quanto somativa na sala de aula. Tendo em vista que a familiaridade com esses conceitos auxilia na elaboração de instrumentos e possibilita às professoras tomar decisões para seu próprio contexto, eles são igualmente imprescindíveis quando trata-se do público infantil e sua variedade etária.

Consideramos que houve fortes evidências de que o módulo analisado contribuiu para suscitar reflexões importantes e despertar nas cursistas a consciência de que é preciso pensar a avaliação a partir de conhecimentos técnicos para que se possa realizar um processo avaliativo justo e apropriado às alunas e à situação de ensino-aprendizagem em que se encontram. 
- Contribuições de um curso EAD para o letramento em avaliação de professores de línguas adicionais para crianças

\section{Considerações finais}

Este artigo discutiu as contribuições de um curso EAD para o Letramento em Avaliação de professoras de línguas adicionais para crianças. Para tanto, foram analisados diários reflexivos redigidos pelas participantes de um curso na modalidade EAD sobre avaliação da aprendizagem de línguas adicionais para crianças.

A análise concentrou-se na busca por indícios de reflexões, nos diários das cursistas, suscitadas por um dos módulos do curso: o módulo sobre os conceitos fundamentais da avaliação - autenticidade, confiabilidade, efeito retroativo, praticalidade e validade -, considerados como essenciais para a elaboração de instrumentos avaliativos formativos, somativos e também em avaliações de larga escala. Para a análise, utilizou-se o software Atlas.ti (Versão 9.0) com base em categorias temáticas a partir de perguntas-guia que orientaram a reflexão das cursistas após cada módulo do curso. Os diários indicaram que o módulo foi bem-sucedido no sentido de provocar reflexões nas cursistas sobre os conceitos abordados, indicando possível ampliação do conhecimento sobre avaliação dessas professoras que, em geral, não possuem formação específica para atuar no ensino de línguas adicionais para crianças.

\section{Referências}

BRASIL. Lei Federal n. 8069, de 13 de julho de 1990. ECA - Estatuto da Criança e do Adolescente. Disponível em: http://www.planalto.gov.br/ccivil_03/leis/I8069.htm. Acesso em: 05 jan. 2021.

BUENO, B. A. G. Chameleon: o jogo de tabuleiro como instrumento de avaliação para a aprendizagem da língua inglesa por crianças. 2020. Trabalho de Conclusão de Curso (Mestrado Profissional em Letras Estrangeiras Modernas) - Centro de Letras e Ciências Humanas, Universidade Estadual de Londrina, Londrina, 2020.

BRINDLEY, G. Language assessment and professional development. In: ELDER, C.; BROWN, A.; GROVE, E.; HILL, K.; IWASHITA, N.; LUMLEY, T.; MCNAMARA, T.; O'LOUGHLIN, K. J. (ed.). Experimenting with uncertainty: Essays in honour of Alan Davies. Cambridge, UK: Cambridge University Press, 2001. p. 126-136.

COOMBE, C. An A to Z of second language assessment: how language teachers understand assessment concepts. London, British Council, 2018. Disponível em: https:// www.britishcouncil.org/z-second-language-assessment. Acesso em: 10 dez. 2020. 
FULCHER, G. Assessment literacy for the language classroom. Language Assessment Quarterly, v. 9, n. 2, p. 113-132, 2012.

GREEN, A. Exploring language assessment and testing. Oxon: Routledge, 2014.

HARDING, L.; KREMMEL, B. Teacher assessment literacy and professional development. In: TSAGARI, D.; BANERJEE, J. (ed.). Handbook of second language assessment. Berlin, Germany: De Gruyter, 2016. p. 413-428.

HASSELGREEN, A. Assessing young learners. In: COOMBE, C.; DAVIDSON, P.; O'SULLIVAN, B.; STOYNOFF, S. (ed.). The Cambridge guide to second language assessment. Cambridge: Cambridge University Press, 2012. p. 171-177.

INBAR-LOURIE, O. Constructing a language assessment knowledge base: A focus on language assessment courses. Language Testing, v. 25, n. 3, p. 385-402, 2008.

ISAACS, T.; ZARAM C.; HERBERT, G.; COOMBS, S. J.; SMITH, C. Key concepts in educational assessment. London: Sage, 2013.

KREMMEL, B.; HARDING, L. Towards a Comprehensive, Empirical Model of Language Assessment Literacy across Stakeholder Groups: Developing the Language Assessment Literacy Survey. Language Assessment Quarterly, v. 17, n. 1, p. 100-120, 2019.

MARCONI, M. A.; LAKATOS, E. M. Fundamentos de metodologia científica. 5. ed. São Paulo: Editora Atlas, 2003.

McKAY, P. Assessing young language learners. Cambridge: Cambridge University Press, 2006.

MINAYO, M. C. S. O desafio do conhecimento. Pesquisa qualitativa em saúde. São Paulo: HUCITEC, 2007.

MISTRY, M.; SOOD, K. English as an additional language in the early years: linking theory to practice. Oxon: Routledge, 2015. 
- Contribuições de um curso EAD para o letramento em avaliação de professores de línguas adicionais para crianças

MORAES, I. T.; BATISTA, E. G. Letramento em avaliação para professores de línguas estrangeiras para crianças: orientações teórico-práticas. Revista Horizontes de Linguística Aplicada, v. 19, n. 2, p. 15-42, 2020.

PELLEGRINO, J. W.; CHUDOWSKY, N.; GLASER, R. (ed.). Knowing what students know: the science and design of educational assessment. Washington, DC: National Academy Press, 2001.

QUEVEDO-CAMARGO, G. Formação de professores de línguas adicionais e letramento em avaliação: breve panorama e desafios para os cursos de licenciatura em LEM no Brasil. Calidoscópio, v. 18, n. 2, p. 435-459, 2020.

QUEVEDO-CAMARGO, G. Efeito retroativo da avaliação na aprendizagem de línguas estrangeiras: que fenômeno é esse? In: MULIK, K. B.; RETORTA, M. S. (org.). Avaliação no ensino-aprendizagem de línguas estrangeiras: diálogos, pesquisas e reflexões. Campinas: Pontes, 2014. p. 77-93.

QUEVEDO-CAMARGO, G.; SCARAMUCCI, M. V. R. O conceito de letramento em avaliação de línguas: origem de relevância para o contexto brasileiro. Linguagem: Estudos e Pesquisas, v. 22, n. 1, p. 225-245, 2018.

REICHMANN, C. L. (org.). Diários reflexivos de professores de línguas: ensinar, escrever, refazer-(se). Campinas: Pontes Editores, 2013.

RETORTA, M. S.; MAROCHI, T. B. Avaliação em línguas estrangeiras: da teoria à prática. Curitiba: CRV, 2018.

$\mathrm{RICH}$, S. Early language learning teacher education. In: GARTON, S.; COPLAND, F. (ed.). The Routledge Handbook of Teaching English to Young Learners. New York, NY: Routledge, 2019, p. 44-59.

SCARAMUCCI, M. V. R. Letramento em avaliação (em contexto de línguas): contribuições para a linguística aplicada, educação e sociedade. In: JORDÃO, C. M. (org.). A linguística aplicada no Brasil: rumos e passagens. Campinas: Pontes, 2016. p. 141-165. 
SHEEHAN, S.; MUNRO, S. Classroom assessment: the development of teachers' cognition. London: British Council, 2019.

SKINNER, R. R. Basic concepts and technical considerations in education assessment: a primer. Washington, DC: Congressional Research Service, 2017.

SOARES, M. Letramento: um tema em três gêneros. São Paulo: Autêntica, 1999.

STIGGINS, R. Assessment literacy. Phi Delta Kappan, v. 72, p. 534-539, 1991.

TAYLOR, L. Communicating the theory, practice and principles of language testing to test stakeholders: some reflections. Language Testing, v. 30, n. 3, p. 403-412, 2013.

TONELLI, J. R. A.; CRISTOVÃO, V. L. L. O Papel dos cursos de letras na formação de professores de inglês para crianças. Calidoscópio, v. 8, n. 1, p. 65-76, 2010.

TONELLI, J. R. A.; QUEVEDO-CAMARGO, G. Teaching EFL to children: reflections on (future) teachers' language assessment literacy. Revista Horizontes de Linguística Aplicada, v. 17, n. 1, p. 63-91, 2018.

TONELLI, J. R. A.; QUEVEDO-CAMARGO, G. Saberes necessários ao professor para avaliar a aprendizagem de crianças na sala de aula de línguas estrangeiras. Fólio: Revista de Letras, v. 11, n. 1, p. 583-607, 2019.

COMO CITAR ESTE ARTIGO: QUEVEDO-CAMARGO, Gladys; TONELLI, Juliana Reichert Assunção. Contribuições de um curso EAD para o letramento em avaliação de professores de línguas adicionais para crianças. Revista do GEL, v. 18, n. 1, p. 230-248, 2021. Disponível em: https://revistadogel.gel.org.br/

Submetido em: 11/02/2021 | Aceito em: 24/02/2021. 